\title{
Paediatric Obsessive-Compulsive Disorder and Comorbid Body Dysmorphic Disorder: Clinical Expression and Treatment Response
}

\author{
Jason I. Racz ${ }^{1}$ Sharna L. Mathieu ${ }^{1} \cdot$ Matthew L. McKenzie ${ }^{1}$ Lara J. Farrell $^{1}$ (D)
}

Accepted: 5 January 2022

(c) The Author(s) 2022

\begin{abstract}
This study explored the expression, occurrence, and treatment outcomes of comorbid body dysmorphic disorder (BDD) in 107 youth (7-17 years) seeking treatment for primary obsessive-compulsive disorder (OCD). In the overall sample, appearance anxiety (AA) was positively associated with OCD-related impairment, severity, symptom frequency, comorbid symptoms, and maladaptive emotion regulation. Comorbid BDD occurred in $9.35 \%$ of youth, equally affected males and females, and was associated with older age. AA negligibly reduced following treatment. Compared to those without (a) comorbid BDD and (b) without any comorbidity, youth with comorbid BDD reported greater social impairment and reduced global functioning but did not differ on the occurrence of comorbid anxiety and mood disorders. OCD response or remission rates did not differ. In youth with comorbid BDD, AA did not significantly reduce following treatment. Results suggest a more severe expression accompanies comorbid BDD in youth with OCD, with BDD persisting following OCD treatment.
\end{abstract}

Keywords Paediatric $\cdot$ Comorbid $\cdot$ Obsessive-compulsive disorder $\cdot$ Body dysmorphic disorder $\cdot$ Presentation

\section{Introduction}

Approximately 3\% of youth experience obsessive-compulsive disorder (OCD) [1], with $25 \%$ of lifetime cases emerging by 14 years old [2]. Paediatric OCD is chronic and possesses a high comorbidity rate [3] that often exacerbates its expression, including increased rates of family accommodation [4], as well as OCD severity and is associated with attenuated outcomes [5]. For example, a study by Storch and colleagues [5] indicated that amongst 96 youth with OCD, $74 \%$ possessed a comorbidity, which was associated with reduced treatment response and remission following cognitive-behavioural therapy (CBT). Indeed, research indicates that specific comorbidities, such as attention-deficit/ hyperactivity disorder, may be associated with a particularly severe and refractory presentation $[4,6]$.

Notably, OCD and obsessive-compulsive and related disorders, such as body dysmorphic disorder (BDD), co-occur at a greater rate relative to the general population [3]. BDD frequently onsets during adolescence and is defined by an

Lara J. Farrell

1.farrell@griffith.edu.au

1 School of Applied Psychology, Griffith University, Parklands Drive, Southport, QLD 4222, Australia extreme preoccupation with perceived appearance defects, accompanied by repetitive behaviours, and significant distress and/or impairment [2]. Within adult OCD samples, comorbid BDD (OCD + BDD) occurs equally across genders [7-9], however, it may be more likely in older youth given the later adolescent onset of BDD relative to OCD [2]. Importantly, it is reported that such a comorbidity encourages a more complex OCD expression, with studies reporting increased OCD symptom severity [7, 8, 10, 11], earlier age of OCD onset $[7,11]$, more substantial impairment in functioning [9], and overall greater comorbidity, including anxiety and mood disorders $[7,8,12]$. For instance, in a study of 901 outpatients with OCD ( $M_{\text {age }}=34.4$ years $)$, $11.4 \%$ experienced comorbid BDD, and these patients tended to be younger, had more severe OCD symptoms, and a higher rate of dysthymia and social phobia [7]. However, to date, there have been no previous studies which have examined the occurrence of BDD exclusively among youth with OCD. This is despite an occurrence of $10.40 \%$ in adult samples [13], suggesting a rate more than four times that of population estimates (i.e., 2.20\%) [14]. Establishing the occurrence and correlates of this common and severe comorbid presentation in youth with OCD is an important step towards improved outcomes. 
Indeed, given the increased complexity and impairment associated with OCD + BDD, it is likely that this presentation may be particularly challenging to treat. Broadly, CBT for the direct treatment of BDD has received empirical support with a meta-analysis of randomised controlled trials (RCT) demonstrating the maintenance of improvements up to four-months after treatment [15]. Studies have highlighted that specific clinical variables associated with adult $\mathrm{OCD}+\mathrm{BDD}$ (e.g., reduced insight and greater depression) do not appear to reduce effectiveness of CBT for adolescents with BDD [16]. The limited literature examining the effectiveness of treating youth with OCD + BDD suggests improvements across conditions following CBT, however outcomes may be unstable. For instance, one case study reported on exposure and response prevention (ERP) with behavioural activation for an adolescent presenting with BDD and comorbid OCD and major depressive disorder, finding an initial reduction in both OCD and BDD severity; however BDD gains diminished after early treatment cessation [17]. Likewise, an observational longitudinal study including 53 participants aged 12 years or older with BDD and comorbid OCD, reported that whilst improvements in OCD symptoms predicted subsequent comorbid BDD remission, clinical BDD persisted in 50\% of participants three months following OCD remission [18]. This possibility, that amongst youth with OCD comorbid BDD may attenuate OCD treatment response, whilst also benefiting to a limited extent from said treatment, warrants further investigation.

\section{The Present Study}

The current study aimed to investigate the clinical expression, occurrence, and treatment outcomes of OCD + BDD in youth with a primary diagnosis of OCD who received intensive CBT for OCD. These aims were achieved by firstly examining associations with BDD symptoms (appearance anxiety) within a sample of youth with OCD. It was hypothesised that appearance anxiety (AA) would be significantly and positively correlated with OCD-related severity, impairment, family accommodation, and symptom frequency; as well as anxiety symptoms, depressive symptoms, externalising symptoms, and maladaptive emotion regulation, and negatively correlated with OCD onset age, insight, adaptive emotion regulation, and global functioning. Further, that AA would decrease significantly from pre-treatment to posttreatment following intensive CBT for youth with OCD.

Secondly, following an exploration of the occurrence of comorbid BDD, we aimed to examine differences across subgroups of youth with either comorbid OCD + BDD, OCD without BDD, or OCD without any comorbidities (OCDonly). The OCD without BDD group was made up of youth without comorbid BDD, with and without other internalising comorbidities. In comparison, youth with OCD and no other comorbidities constituted the OCD-only group. It was hypothesised that compared to youth with OCD without BDD and youth with OCD-only, those with comorbid OCD + BDD would have significantly higher OCD-related severity and impairment, maladaptive emotion regulation, poorer global functioning, and would more likely have comorbid anxiety and mood disorders (relative to youth with OCD without BDD). Further, it was hypothesised that youth with comorbid OCD + BDD would be less likely to be OCD treatment responders and remitters at post-treatment and three-month follow-up relative to other subgroups, although youth with OCD + BDD would report a significant decrease in AA symptoms following intensive CBT for OCD.

\section{Methods}

\section{Participants}

Participants included 107 youth (53.27\% female) aged 7 to 17 years $\left(M_{\mathrm{age}}=11.94, S D=2.48\right)$, with a primary diagnosis of OCD, and their parents, recruited for OCD treatment through community advertising or referral. Youth were recruited for a larger treatment $\mathrm{RCT}$ and met the inclusion criteria: primary diagnosis of $\mathrm{OCD}$, parent willing to participate, and stable (i.e., 12 weeks) medication dose before treatment. Exclusion criteria included: the presence of psychosis, intellectual disability, active suicidal ideation, concurrent psychotherapy, or non-proficiency in the English language.

To address subgroup analyses the OCD + BDD clinical subsample $\left(n=10,50 \%\right.$ female, $\left.M_{\text {age }}=13.80, S D=2.49\right)$ was paired with OCD without BDD $(n=10,50 \%$ female, $\left.M_{\text {age }}=13.40, S D=2.17\right)$ and OCD-only controls $(n=10$, $70 \%$ female, $M_{\text {age }}=12.70, S D=2.36$ ) of approximately matched age and gender, via consecutive enrolments into the trial. Youth with autism spectrum disorder or attention-deficit/hyperactivity disorder were excluded from these controls given their more severe OCD clinical expression $[4,19]$.

\section{Measures}

\section{Diagnostic Measures}

Anxiety Disorders Interview Schedule for DSM-IV-Parent Version (ADIS-IV-P) [20]. The ADIS-IV-P is a structured parent-interview, assessing child psychological disorders and severity, according to diagnostic criteria [21], and was used to diagnose OCD, and comorbid anxiety, mood, and externalising disorders. Diagnostic decisions were made according to the ADIS-IV-P protocol, based on the reported presentation of symptoms and a severity rating on an 8-point scale. The ADIS-IV-P displays acceptable convergent 
validity $(r \geq .22)$ with the Children's Yale-Brown Obsessive-Compulsive Scale symptom checklist [22] and excellent interrater agreement in past analyses of this sample $(\kappa \geq .84)$ [19].

Body Dysmorphic Disorder Questionnaire for Adolescents (BDDQ-A) [23]. The BDDQ-A is a four-item dichotomous self-report measure assessing BDD diagnostic criteria [21]. The adult version reports $100 \%$ sensitivity and $89 \%$ specificity in individuals with a psychiatric diagnosis [23]. Further, in Australian youth the BDDQ-A has demonstrated acceptable reliability $(\alpha=.75)$ [24], and in those reporting high levels of BDD symptoms, known-groups validity [25].

\section{Symptom Measures}

Appearance Anxiety Inventory (AAI) [26]. The AAI is a 14-item self-report measure of AA on a 5-point Likert scale. A total score of 20 or above represents clinical levels [27]. The AAI has demonstrated convergent validity with the Cosmetic Procedure Screening [26] and excellent internal consistency in the current study $(\alpha=.94)$.

Children's Yale-Brown Obsessive-Compulsive Scale (CY-BOCS) [28]. The CY-BOCS is a child and parent semistructured clinical interview of OCD severity rated using 10-items on a 5-point Likert scale across both the Obsession and Compulsion subscales. Symptom insight was measured using one additional item from the CY-BOCS supplementary impairment items. The CY-BOCS displays good interrater reliability $(\kappa=.66)$ and convergent validity with selfreport [28].

Child OCD Impact Scale-Child (COIS-C) [29]. The COIS-C is a 57 -item child self-report measure of OCDrelated impairment in psychosocial functioning across School, Social, and Home subscales on a 4-point Likert scale. The COIS-C has displayed moderate convergent validity $(r=.46)$ with the CY-BOCS symptom checklist [29], and in the current study, excellent internal consistency across the subscales and total $(\alpha>.91)$.

Children's Global Assessment Scale (CGAS) [30]. The CGAS is a single-item clinician-rated measure of global functioning in youth over the previous two weeks, on a 100 -point scale with a score equal to or above 70 indicating normal functioning. The CGAS possesses strong interrater reliability (intraclass correlation coefficient of .73) [31] and good convergent validity with the Child Behaviour Checklist [32].

Obsessive-Compulsive Inventory-Child Version (OCICV) [33]. The OCI-CV is a 21-item self-report measure of paediatric OCD symptom frequency on a 3-point Likert scale across the subscales of Washing, Doubting/Checking, Hoarding, Ordering, Obsessing, and Neutralising subscales. The OCI-CV has demonstrated good divergent validity with the Children's Depression Inventory [33] and, in the current study, acceptable internal consistency across most subscales and in total $(\alpha>.78)$. Whilst the Neutralising subscale $(\alpha=.66)$ demonstrated unstable internal consistency it remained usable considering the exploratory purpose of the current study [34].

Family Accommodation Scale for OCD-Self-Rated Version (FAS-SR) [35]. The FAS-SR is a parent-rated 19-item measure of the frequency and severity of family accommodation of obsessive-compulsive behaviours over the previous month on a 5-point Likert scale. The FAS-SR has displayed good convergent validity with OCD severity [35] and excellent internal consistency in the current study $(\alpha=.91)$.

Multidimensional Anxiety Scale for Children 2nd Edition-Self Report (MASC 2-SR) [36]. The MASC 2-SR is a 50-item child self-report measure of the frequency and severity of anxiety symptoms in youth on a 4-point Likert scale. The MASC 2-SR displays convergent validity with the Beck Youth Inventory Anxiety subscale [37] and the total score possessed excellent internal consistency $(\alpha=.92)$ in the current study.

Child Depressive Inventory 2nd Edition: Self-Report (CDI 2: SR) [38]. The CDI 2: SR is a 28-item child selfreport measure of the frequency and severity of depressive symptoms on a 3-point Likert scale. The CDI 2: SR displays discriminant validity in community samples [39]. The total score possessed acceptable internal consistency $(\alpha=.87)$ in the current study.

Child Behaviour Checklist for Ages 6-18 (CBCL/6-18) [40]. The CBCL/6-18 is a 113-item parent-report questionnaire assessing the frequency of behaviours associated with childhood emotional and behavioural disorders, measured on a 3-point Likert scale. The CBCL/6-18 displays convergent validity with various validated measures of psychopathological disorders [41] and excellent internal consistency $(\alpha=.91)$ across the Externalising domain used in the current study.

Cognitive Emotion Regulation Questionnaire (CERQ) [42]. The CERQ is a 36-item self-report measure of cognitive emotional coping strategies in adolescents (i.e., 12 years or older) across adaptive (Acceptance, Positive Refocusing, Refocus on Planning, Positive Reappraisal, and Putting into Perspective) and maladaptive (Self-Blame, Rumination, Catastrophising, and Other-Blame) subscales. For children (i.e., 11 years or younger) different item wording was used (i.e., the CERQ-k) [43]. Items are scored on a 5-point Likert scale. Both adolescent and child versions have demonstrated factorial and criterion validity, respectively [44, 45]. For the current study, the adaptive emotion regulation score had good internal consistency $(\alpha>.81)$. To form a maladaptive emotion regulation score, the four maladaptive subscales were summed with the Expressive Suppression subscale of the Emotion Regulation Questionnaire for Children and Adolescents (ERQ-CA) [46]. The ERQ-CA measures inhibition of emotion-expressive behaviour across four items on 
a 5-point Likert scale. This maladaptive emotion regulation score had good internal consistency for children and adolescents $(\alpha>.74)$.

\section{Procedure}

Ethical approval for the current procedure was granted by the institution's human research ethics committee. Participants, including their parents, provided written informed consent. Demographical information was collected and a parent diagnostic interview (i.e., ADIS-IV-P) conducted via telephone, to confirm diagnostic eligibility, which was subject to clinical consensus overseen by a senior clinical psychologist specialising in paediatric OCD (LJF). Ineligible youth were referred to appropriate treatment services, whilst eligible youth completed clinician symptom interviews faceto-face, and questionnaire measures online. Participants completed three intensive three-hour CBT-ERP sessions, over three weeks, with an additional booster session one month later. These sessions were delivered by supervised therapists that were clinically trained postgraduate psychology students undergoing their final year in training or were fully registered. As part of the trial, participants were randomised to a placebo or d-cycloserine augmented condition, which yielded a non-significant time $\times$ treatment effect on all primary outcomes [47] and consequently was not controlled for in the current study.

\section{Overview of Analyses}

To examine hypothesis one, bivariate correlations between AA and clinical characteristics were calculated, using the 82 participants $\left(M_{\mathrm{age}}=12.06, S D=2.48\right)$ whose AA was assessed at pre-treatment $(47.60 \%$ male, $9.80 \%$ with comorbid BDD). Exclusion of one OCD + BDD participant's extreme and unreliable parent-report data reduced the sample to 81 for parent-report measures. Given poor normality [48], to control for type one error [49, 50] AA was logarithmically transformed with a conservative effect. To examine subgroup analyses, a series of Kruskal-Wallis ANOVAs assessed OCD severity and impairment between the OCD + BDD, OCD without BDD and OCD-only subsamples. As is common within small clinical samples, adjustments for multiple comparisons often inflate type two error [51], therefore adjustments were not made to alpha rate for multiple comparisons. A series of follow-up Mann-Whitney $U$ tests compared the OCD $+\mathrm{BDD}$ group to the OCD without BDD and OCD-only groups. To examine treatment response, a reduction in OCD severity of $25 \%$ indicated response and a $50 \%$ reduction, along with a raw score below 14 , signified remission [52].
Given the hypothesis-generating aim and that the data were missing at random, $\chi^{2}(1082)=1040.63, p=.812$, itemlevel missing data were replaced by the participant's scale mean, and further construct-level missing repeated measures were imputed by carrying the last observation forward to maximise conservative outcomes. Any remaining missing data was excluded pairwise to maximise statistical power [53] and effect sizes were reported regardless of statistical significance as a measure of clinical meaningfulness [54].

\section{Results}

\section{BDD Symptoms (AA) in Youth with OCD: Clinical Correlates}

Correlations between AA (untransformed $M=9.54$, $S D=10.66$; transformed $M=0.82, S D=0.45$ ) and measures of clinical expression, can be found in Table 1, alongside descriptive statistics. Partially supporting hypothesis one,

Table 1 Correlations with appearance anxiety and descriptive statistics

\begin{tabular}{|c|c|c|c|}
\hline Variable $(n)$ & $r$ & $M$ & $S D$ \\
\hline \multicolumn{4}{|l|}{ OCD clinical expression } \\
\hline Age of onset (79) & .14 & 8.70 & 3.02 \\
\hline Insight (82) & -.00 & 1.57 & 1.01 \\
\hline Impairment (82) & $.36^{* *}$ & 44.15 & 30.72 \\
\hline Family accommodation (79) & .06 & 25.72 & 17.87 \\
\hline \multicolumn{4}{|l|}{ Severity (82) } \\
\hline Obsessions & .15 & 13.34 & 2.42 \\
\hline Compulsions & $.24 *$ & 13.84 & 2.31 \\
\hline Total & $.23 *$ & 27.20 & 4.06 \\
\hline \multicolumn{4}{|l|}{ Symptom frequency (82) } \\
\hline Washing & .06 & 3.16 & 2.26 \\
\hline Doubting & $.33 * *$ & 3.97 & 2.82 \\
\hline Hoarding & .19 & 1.81 & 1.66 \\
\hline Ordering & $.31 * *$ & 2.79 & 1.70 \\
\hline Obsessing & $.25^{*}$ & 3.94 & 2.19 \\
\hline Neutralising & $.32 * *$ & 1.71 & 1.64 \\
\hline Total frequency & $.41 * * *$ & 17.37 & 7.26 \\
\hline \multicolumn{4}{|l|}{ Comorbidity symptoms } \\
\hline Anxiety (80) & $.32 * *$ & 72.45 & 22.34 \\
\hline Depressive (80) & $.46 * * *$ & 12.45 & 7.75 \\
\hline Externalising (79) & .18 & 8.74 & 8.44 \\
\hline \multicolumn{4}{|l|}{ Emotion regulation } \\
\hline Adaptive (60) & -.06 & 52.69 & 13.84 \\
\hline Maladaptive (58) & $.53 * * *$ & 45.29 & 11.15 \\
\hline Global functioning (78) & .05 & 53.59 & 6.79 \\
\hline
\end{tabular}

$O C D$ obsessive-compulsive disorder $* p<.05 . * * p<.01 . * * * p<.001$ 
AA was significantly positively correlated with OCD-related impairment, severity (compulsions and total), and symptom frequency (doubting, ordering, obsessing, neutralising, and total), alongside anxiety and depressive symptoms, and maladaptive emotion regulation.

\section{BDD Symptoms (AA) Following OCD Treatment}

Supporting hypothesis two, within those who completed AA at pre-treatment $(n=82)$, AA was significantly lower at posttreatment $(M=8.05, S D=10.17)$ relative to pre-treatment $(M=9.54, S D=10.66), t(81)=2.56, p=.012, d=.14$.

\section{The Occurrence of BDD in Youth with OCD}

Within the overall treatment-seeking sample $(N=107)$, clinical BDD occurred in 10 individuals at a frequency of $9.35 \%$, $95 \%$ confidence interval $[3.83,14.86]$. Those with comorbid BDD $(M=13.80, S D=2.49)$ were significantly older than those without BDD $(M=11.75, S D=2.41), t(105)=-2.55$, $p=.012, d=.85$. Gender frequency (male or female) did not differ, $p=1.00, \phi=.02$, between participants with $(50.0 \%$ male) and without BDD ( $46.4 \%$ male).

\section{Comorbid OCD and BDD: Symptoms, Functioning, and Comorbidity}

The Kruskal-Wallis ANOVAs and follow-up Mann Whitney $U$ tests assessing OCD severity and impairment between the subgroups are presented in Tables 2 and 3, respectively, alongside descriptive statistics to ease interpretability. Significant omnibus differences emerged on OCD severity (obsessions and total), OCD-related impairment (school, social, and total), adaptive emotion regulation, and global functioning. Partially supporting hypothesis three, the OCD + BDD group ranked significantly higher on OCD-related impairment in the social domain and lower on global functioning than both groups, higher on school and total OCD-related impairment than the OCD-only group, and lower on adaptive emotion regulation and higher on OCD obsession and total OCD severity than the OCD without BDD group.

Fisher's exact tests assessing comorbidity frequency between groups revealed no significant differences for social anxiety disorder, specific phobia, panic disorder, agoraphobia, generalised anxiety disorder, post-traumatic stress disorder, dysthymia, and major depressive disorder across youth with and without comorbid BDD, failing to support hypothesis four. The comorbid group was higher on the frequency of all disorders, except for dysthymia, where it was lower. Importantly, a trend for greater frequency of comorbid social anxiety disorder was observed $(p=.057, \phi=.52)$ in youth with comorbid BDD (60\%) relative to youth without BDD (10\%).

Table 2 Descriptive statistics and Kruskal-Wallis ANOVAs assessing measures of OCD severity and impairment between-groups

\begin{tabular}{|c|c|c|c|c|c|c|}
\hline \multirow[t]{2}{*}{ Variable } & \multicolumn{3}{|l|}{ Mean rank, $M d n(\mathrm{IQR})$} & \multirow[t]{2}{*}{$H^{\mathrm{a}}$} & \multirow[t]{2}{*}{$n^{\mathrm{b}}$} & \multirow[t]{2}{*}{$\eta^{2}$} \\
\hline & $\mathrm{OCD}+\mathrm{BDD}(n=10)$ & OCD without BDD $(n=10)$ & OCD-only $(n=10)$ & & & \\
\hline \multicolumn{7}{|l|}{ OCD severity } \\
\hline Obsessions & $20.85,15.00(2.00)$ & $10.90,13.00(1.50)$ & $14.75,14.00(5.25)$ & $6.67 *$ & $10,10,10$ & .23 \\
\hline Compulsions & $18.95,15.00(4.25)$ & $15.40,14.50(3.25)$ & $12.15,14.50(4.75)$ & 3.05 & $10,10,10$ & .11 \\
\hline Total & $21.25,30.50(3.50)$ & $12.00,27.00(3.50)$ & $13.25,29.00(9.50)$ & $6.58 *$ & $10,10,10$ & .23 \\
\hline \multicolumn{7}{|c|}{ OCD-related impairment } \\
\hline School & $20.22,23.00(17.53)$ & $14.39,11.00(17.00)$ & $7.39,9.00(9.00)$ & $11.88 * *$ & $9,9,9$ & .46 \\
\hline Social & $19.56,30.00(21.00)$ & $11.00,10.50(17.50)$ & $9.67,8.00(15.50)$ & $8.79 *$ & $9,8,9$ & .35 \\
\hline Home & $17.44,28.00(19.00)$ & $12.88,19.50(23.50)$ & $10.11,14.00(17.50)$ & 4.23 & $9,8,9$ & .17 \\
\hline Total & $19.00,81.00(53.53)$ & $12.31,40.00(44.25)$ & $9.06,30.00(42.88)$ & $7.89 *$ & $9,8,9$ & .32 \\
\hline \multicolumn{7}{|l|}{ Emotion regulation } \\
\hline Adaptive & $6.86,41.00(18.00)$ & $17.36,38.00(24.50)$ & $10.44,51.00(10.25)$ & $9.55^{* *}$ & $7,7,8$ & .45 \\
\hline Maladaptive & $13.43,49.00(15.00)$ & $13.57,44.00(35.00)$ & $8.00,38.00(24.50)$ & 3.66 & $7,7,8$ & .17 \\
\hline Global functioning & $9.70,50.00(5.00)$ & $17.80,52.50(10.00)$ & $19.00,55.00(11.25)$ & $7.17 *$ & $10,10,10$ & .25 \\
\hline
\end{tabular}

$d f=2$. $O C D$ obsessive-compulsive disorder; $I Q R$ interquartile range; $O C D+B D D$ obsessive-compulsive disorder with comorbid body dysmorphic disorder; $O C D$-only obsessive-compulsive disorder without any comorbidities

${ }^{\text {a } K r u s k a l-W a l l i s ~ t e s t ~ s t a t i s t i c ~ c o r r e c t e d ~ f o r ~ t i e s ~}$

${ }^{\mathrm{b}} \mathrm{OCD}+\mathrm{BDD}$, OCD without BDD, and OCD-only pairwise subsample sizes

$* p<.05, * * p<.01$ 
Table 3 Follow-up MannWhitney $\mathrm{U}$ tests assessing OCD-related impairment between-groups

\begin{tabular}{|c|c|c|c|c|c|}
\hline \multirow[t]{2}{*}{ Variable } & \multicolumn{3}{|l|}{ Mean rank } & \multirow[t]{2}{*}{$U$} & \multirow[t]{2}{*}{$r$} \\
\hline & $\mathrm{OCD}+\mathrm{BDD}$ & $\begin{array}{l}\text { OCD without } \\
\text { BDD }\end{array}$ & OCD-only & & \\
\hline \multirow[t]{2}{*}{ Obsession OCD severity } & 14.25 & 6.75 & - & $12.50 * *$ & .65 \\
\hline & 12.10 & - & 8.90 & 34.00 & .28 \\
\hline \multirow[t]{2}{*}{ Total OCD severity } & 13.95 & 7.05 & - & $15.50 * *$ & .59 \\
\hline & 12.80 & - & 8.20 & 27.00 & .39 \\
\hline \multirow[t]{2}{*}{ School OCD-related impairment } & 11.67 & 7.33 & - & 21.00 & .41 \\
\hline & 13.56 & - & 5.44 & $4.00 * * *$ & .76 \\
\hline \multirow[t]{2}{*}{ Social OCD-related impairment } & 11.78 & 5.88 & - & $11.00^{*}$ & .58 \\
\hline & 12.78 & - & 6.22 & $11.00 * *$ & .62 \\
\hline \multirow[t]{2}{*}{ Total OCD-related impairment } & 11.22 & 6.50 & - & 16.00 & .47 \\
\hline & 12.78 & - & 6.22 & $11.00 * *$ & .61 \\
\hline \multirow[t]{2}{*}{ Adaptive emotion regulation } & 4.43 & 10.57 & - & $3.00 * *$ & .74 \\
\hline & 6.43 & - & 9.38 & 17.00 & .33 \\
\hline \multirow[t]{2}{*}{ Global functioning } & 7.75 & 13.25 & - & $22.50^{*}$ & .49 \\
\hline & 7.45 & - & 13.55 & $19.50 *$ & .54 \\
\hline
\end{tabular}

Medians, interquartile ranges, and subsample sizes are reported in Table 2. Exact two-tailed significance was reported. $O C D$ obsessive-compulsive disorder; $O C D+B D D$ obsessive-compulsive disorder with comorbid body dysmorphic disorder; $O C D$-only obsessive-compulsive disorder without any comorbidities; dash (-) not compared in analysis

$* p<.05 . * * p<.01 . * * * p<.001$

\section{Comorbid OCD and BDD: Treatment Response}

Fisher's exact tests assessing OCD response and remission frequency at post-treatment and three-month follow-up between the groups are presented in Table 4. No significant differences in response or remission frequency emerged at post-treatment or three-month follow-up, opposing hypothesis five.

Hypothesis six was not supported, as within the OCD + BDD subgroup BDD symptoms (AA) did not rank significantly differently between pre-treatment $(M d n=27.50$, $I Q R=32.00)$ and post-treatment $(M d n=22.00, I Q R=25.25)$, $T=1.00, n$-ties $=5, p=.080, r=.44$. Specifically, relative to pre-treatment, the AA of four participants ranked lower at post-treatment (sum of ranks $=14.00$ ), whilst only one participant ranked higher (sum of ranks $=1.00$ ), and three participants reported no difference.

\section{Discussion}

This study aimed to explore the clinical expression, occurrence, and treatment outcomes of OCD + BDD in a sample of treatment-seeking youth with a primary diagnosis of OCD. It was broadly hypothesised that BDD symptoms and comorbid BDD diagnoses would be associated with greater severity and impairment, comorbid anxiety and mood disorders, and a reduced response to OCD treatment, whilst BDD symptoms would reduce from pre-treatment to post-treatment.
Table 4 Fisher's exact tests assessing OCD response and remission frequency betweengroups

\begin{tabular}{llllll}
\hline OCD response & \multicolumn{2}{l}{ Frequency } & \multirow{2}{*}{$p$} & $w$ \\
\cline { 2 - 4 } & OCD +BDD & OCD without BDD & OCD-only & & \\
\hline Post-treatment & & & & & \\
$\quad$ Response & $40.00 \%$ & $60.00 \%$ & $80.00 \%$ & .248 & .33 \\
$\quad$ Remission & $30.00 \%$ & $40.00 \%$ & $70.00 \%$ & .272 & .34 \\
Three-month follow-up & & & & & \\
Response & $50.00 \%$ & $70.00 \%$ & $80.00 \%$ & .500 & .27 \\
Remission & $40.00 \%$ & $50.00 \%$ & $50.00 \%$ & 1.00 & .09 \\
\hline
\end{tabular}

$n=30 . O C D+B D D$ obsessive-compulsive disorder with comorbid body dysmorphic disorder; $O C D$-only obsessive-compulsive disorder without any comorbidities 
In the overall sample, hypothesised positive associations between BDD symptoms and OCD-related impairment, severity, and symptom frequency alongside anxiety and depressive symptoms and maladaptive emotion regulation, suggests that even subclinical BDD symptoms may be associated with a more complex and severe paediatric OCD presentation. However, the absence of several predicted associations (i.e., family accommodation, insight etc.) indicate that this may occur only in specific domains or may be worse in older populations $[55,56]$. Regarding treatment outcomes, the significant, but not meaningful, reduction in AA from pre-treatment to post-treatment provided partial support for the second hypothesis.

Nearly one in 10 youth with OCD experienced comorbid BDD in the current sample, much greater than previous estimates in the general adolescent population [14]. Youth with $\mathrm{OCD}+\mathrm{BDD}$ were older than those without BDD, but gender frequency did not differ. Amongst these comorbid youth, subgroup analyses partially supported hypothesis three, providing preliminary evidence of the association between this comorbidity and impairment in paediatric OCD. Specifically, BDD comorbid youth reported higher OCD-related impairment within social contexts and reduced levels of global functioning, beyond that accounted for by comorbidity alone. This is concerning, given the lifelong impact of disruptions to psychosocial development [57]. Moreover, greater OCD obsession and total severity, alongside lower adaptive emotion regulation, relative to those without BDD suggests the similarities between these obsessive-compulsive and related disorders may encourage a more severe presentation. Whilst the absence of increases in mood or anxiety disorders in youth with OCD + BDD fails to support hypothesis four, meaningful effects suggest a trend toward greater overall comorbidity. In particular, social anxiety disorder occurred at a higher rate in such individuals (i.e., $60 \%$ ) relative to those with $\mathrm{OCD}$ without $\mathrm{BDD}$ (i.e., $10 \%$ ), suggesting such findings in adults with OCD + BDD $[7,8]$ may be present in youth. Similarly, the OCD + BDD group did not significantly differ on OCD response or remission, opposing hypothesis five but mirroring findings from adult inpatients [11]. However, meaningful differences signify a trend toward poorer initial response for youth with OCD + BDD (i.e., 40\%) relative to those without comorbid BDD (i.e., 60\%) and no comorbidities (i.e., 80\%). Both these trends beckon further investigation in an adequately powered analysis, to clarify the effect comorbid BDD has on overall comorbidity and treatment outcomes. Finally, failing to support hypothesis six, the OCD + BDD group did not report a significant reduction in AA following treatment, with most continuing to report clinical levels at post-treatment, supporting findings that BDD symptoms largely persist when OCD reduces in comorbid patients [18]. Together with no meaningful reduction in the overall sample, these results emphasise that this comorbid presentation warrants a modularised condition-specific treatment to lead to meaningful BDD improvements [58].

\section{Limitations and Future Research}

Despite this study's large sample of youth with paediatric OCD and analyses across comorbid control groups allowing the unique effects of comorbid BDD to be disentangled from overall comorbidity, several limitations exist. The lack of a primary BDD without comorbidity control made disentangling the additive effect of BDD, from that of a unique OCD + BDD expression, impossible. Secondly, small exploratory subsamples likely resulted in several meaningful differences failing to reach significance. Finally, given the exploratory aim, carrying last observations forward for missing data aimed to estimate outcomes conservatively, however, given attrition often increases alongside severity, generalisability may be limited for severe presentations [59]. Nevertheless, these results extend several adult findings into youth, providing a hypothesis-generating framework for exploration in adequately powered samples. Future studies should consider controlling for the additive effects of BDD, as doing so would improve our understanding of the unique effects OCD + BDD comorbidity have on clinical expression and treatment outcomes.

\section{Conclusions and Implications}

As one of the first explorations of comorbid BDD in paediatric $\mathrm{OCD}$, these findings reinforce that practitioners should remain aware that the often hidden [60] and underdiagnosed [61] BDD appears relatively common within paediatric OCD and is associated with worse impairment. Furthermore, as BDD symptoms appear to persist following OCD treatment, practitioners should consider using a unique CBT protocol for its treatment in comorbid youth.

\section{Summary}

The clinical expression, occurrence, and treatment outcomes of comorbid BDD were explored in a large, treatment-seeking sample of youth with a primary diagnosis of OCD. Participants $(N=107)$ aged $7-17$ years $\left(M_{\text {age }}=11.94,46.70 \%\right.$ male) were recruited for OCD treatment as part of a larger randomised-controlled trial. Study measures were completed at pre-treatment, post-treatment, and three-month followup. Among the 107 youth with OCD, greater AA was significantly associated with greater OCD-related impairment, severity, symptom frequency, anxious and depressive symptoms, and maladaptive emotion regulation. Comorbid BDD occurred in $9.35 \%$ of youth with OCD, equally affecting both 
males and females. Moreover, those with comorbid BDD were older than those without. AA significantly reduced following OCD treatment, although this difference was negligible in size. For subgroup analyses, youth with comorbid BDD were compared to two age and gender matched subsamples of youth, including those (a) without comorbid BDD and (b) without any comorbidity. Youth with comorbid BDD reported greater OCD-related impairment in social settings and reduced global functioning relative to those with and without other comorbidities but did not significantly differ from those without comorbid BDD on the occurrence of comorbid anxiety and mood disorders. OCD response or remission rate did not differ across the subsamples with and without comorbid BDD at post-treatment or three-month follow-up. Furthermore, youth with comorbid BDD did not report a significant reduction in body dysmorphic symptoms following OCD treatment. This study suggests comorbid BDD is common in youth with OCD, relative to previous adolescent general population estimates, is accompanied by a unique and more severe clinical expression, and that BDD symptoms appear to persist following the treatment of OCD.

Funding Open Access funding enabled and organized by CAUL and its Member Institutions. This study was partially supported by funding from the National Health and Medical Research Council (APP1058025). The first author was a recipient of an Australian Government Research Training Program Scholarship for the completion of their ongoing postgraduate research studies. The funding body and academic scholarship providers were not involved in the: study design; collection, analyses, and interpretation of data; writing; or submission process.

\section{Declarations}

Conflict of interest Given their role as an Associate Editor, L. J. Farrell was not involved in the peer-review of this article. The authors declare they have no other conflicts of interest.

Ethical Approval All procedures performed in studies involving human participants were in accordance with the ethical standards of Griffith University's Human Research Ethics Committee and with the 1964 Helsinki declaration and its later amendments or comparable ethical standards.

Informed Consent Informed consent was obtained from all individual participants included in the study.

Open Access This article is licensed under a Creative Commons Attribution 4.0 International License, which permits use, sharing, adaptation, distribution and reproduction in any medium or format, as long as you give appropriate credit to the original author(s) and the source, provide a link to the Creative Commons licence, and indicate if changes were made. The images or other third party material in this article are included in the article's Creative Commons licence, unless indicated otherwise in a credit line to the material. If material is not included in the article's Creative Commons licence and your intended use is not permitted by statutory regulation or exceeds the permitted use, you will need to obtain permission directly from the copyright holder. To view a copy of this licence, visit http://creativecommons.org/licenses/by/4.0/.

\section{References}

1. James SC, Farrell LJ, Zimmer-Gembeck MJ (2017) Description and prevalence of OCD in children and adolescents. In: Abramowitz JS, McKay D, Storch EA (eds) The Wiley handbook of obsessive compulsive disorders. John Wiley \& Sons Ltd., Chichester, pp 5-23

2. American Psychiatric Association (2013) Diagnostic and statistical manual of mental disorders, 5th edn. American Psychiatric Association, Arlington

3. Lochner C, Fineberg NA, Zohar J, van Ameringen M, JuvenWetzler A, Altamura AC et al (2014) Comorbidity in obsessive-compulsive disorder (OCD): a report from the International College of Obsessive-Compulsive Spectrum Disorders (ICOCS). Compr Psychiatry 55(7):1513-1519. https://doi.org/ 10.1016/j.comppsych.2014.05.020

4. Farrell LJ, Lavell C, Baras E, Zimmer-Gembeck MJ, Waters AM (2020) Clinical expression and treatment response among children with comorbid obsessive compulsive disorder and attention-deficit/hyperactivity disorder. J Affect Disord 266:585594. https://doi.org/10.1016/j.jad.2020.01.144

5. Storch EA, Merlo LJ, Larson MJ, Geffken GR, Lehmkuhl HD, Jacob ML et al (2008) Impact of comorbidity on cognitivebehavioral therapy response in pediatric obsessive-compulsive disorder. J Am Acad Child Adolesc Psychiatry 47(5):583-592. https://doi.org/10.1097/chi.0b013e31816774b1

6. Farrell L, Waters A, Milliner E, Ollendick T (2012) Comorbidity and treatment response in pediatric obsessive-compulsive disorder: a pilot study of group cognitive-behavioral treatment. Psychiatry Res 199(2):115-123. https://doi.org/10.1016/j.psych res.2012.04.035

7. Conceição Costa DL, Chagas Assunção M, Arzeno Ferrão Y, Archetti Conrado L, Hajaj Gonzalez C, Franklin Fontenelle L et al (2012) Body dysmorphic disorder in patients with obsessive-compulsive disorder: prevalence and clinical correlates. Depress Anxiety 29(11):966-975. https://doi.org/10.1002/da. 21980

8. Diniz JB, Costa DL, Cassab RC, Pereira CA, Miguel EC, Shavitt RG (2014) The impact of comorbid body dysmorphic disorder on the response to sequential pharmacological trials for obsessivecompulsive disorder. J Psychopharmacol 28(6):603-611. https:// doi.org/10.1177/0269881113512042

9. Phillips KA, Pinto A, Menard W, Eisen JL, Mancebo M, Rasmussen SA (2007) Obsessive-compulsive disorder versus body dysmorphic disorder: a comparison study of two possibly related disorders. Depress Anxiety 24(6):399-409. https://doi.org/10. 1002/da. 20232

10. Simeon D, Hollander E, Stein DJ, Cohen L, Aronowitz B (1995) Body dysmorphic disorder in the DSM-IV field trial for obsessivecompulsive disorder. Am J Psychiatry 152(8):1207-1209. https:// doi.org/10.1176/ajp.152.8.1207

11. Stewart SE, Stack DE, Wilhelm S (2008) Severe obsessive-compulsive disorder with and without body dysmorphic disorder: clinical correlates and implications. Ann Clin Psychiatry 20(1):33-38. https://doi.org/10.1080/10401230701844463

12. Frare F, Perugi G, Ruffolo G, Toni C (2004) Obsessive-compulsive disorder and body dysmorphic disorder: a comparison of clinical features. Eur Psychiatry 19(5):292-298. https://doi.org/ 10.1016/j.eurpsy.2004.04.014 
13. Frias Á, Palma C, Farriols N, González L (2015) Comorbidity between obsessive-compulsive disorder and body dysmorphic disorder: prevalence, explanatory theories, and clinical characterization. Neuropsychiatr Dis Treat 11:2233-2244. https://doi. org/10.2147/ndt.S67636

14. Veale D, Gledhill LJ, Christodoulou P, Hodsoll J (2016) Body dysmorphic disorder in different settings: a systematic review and estimated weighted prevalence. Body Image 18:168-186. https:// doi.org/10.1016/j.bodyim.2016.07.003

15. Harrison A, Fernández de la Cruz L, Enander J, Radua J, MataixCols D (2016) Cognitive-behavioral therapy for body dysmorphic disorder: a systematic review and meta-analysis of randomized controlled trials. Clin Psychol Rev 48:43-51. https://doi.org/10. 1016/j.cpr.2016.05.007

16. Krebs G, Fernández de la Cruz L, Monzani B, Bowyer L, Anson M, Cadman J et al (2017) Long-term outcomes of cognitivebehavioral therapy for adolescent body dysmorphic disorder. Behav Ther 48(4):462-473. https://doi.org/10.1016/j.beth.2017. 01.001

17. Le T-AP, Merricks K, Nadeau JM, Ramos A, Storch EA (2017) Intensive exposure and response prevention for adolescent body dysmorphic disorder with comorbid obsessive-compulsive disorder and major depressive disorder. Clin Case Stud 16(6):480-496. https://doi.org/10.1177/1534650117737176

18. Phillips KA, Stout RL (2006) Associations in the longitudinal course of body dysmorphic disorder with major depression, obsessive-compulsive disorder, and social phobia. J Psychiatr Res 40(4):360-369. https://doi.org/10.1016/j.jpsychires.2005.10.001

19. Griffiths DL, Farrell LJ, Waters AM, White SW (2017) ASD traits among youth with obsessive-compulsive disorder. Child Psychiatry Hum Dev 48:911-921. https://doi.org/10.1007/ s10578-017-0714-3

20. Silverman WK, Albano AM (1996) Anxiety disorders interview schedule for DSM-IV: parent interview schedule. Oxford University Press, New York

21. American Psychiatric Association (1994) Diagnostic and statistical manual of mental disorders, 4th edn. American Psychiatric Association, Arlington

22. Gallant J, Storch EA, Merlo LJ, Ricketts ED, Geffken GR, Goodman WK et al (2008) Convergent and discriminant validity of the Children's Yale-Brown Obsessive Compulsive scale-symptom checklist. J Anxiety Disord 22(8):1369-1376. https://doi.org/10. 1016/j.janxdis.2008.01.017

23. Phillips KA (2005) The broken mirror: understanding and treating body dysmorphic disorder, 2nd edn. Oxford University Press, New York

24. Roberts C, Zimmer-Gembeck MJ, Farrell LJ (2019) The multidimensional youth body dysmorphic inventory: development and preliminary validation. Child Psychiatry Hum Dev 50:927-939. https://doi.org/10.1007/s10578-019-00893-6

25. Schneider SC, Turner CM, Mond J, Hudson JL (2017) Prevalence and correlates of body dysmorphic disorder in a community sample of adolescents. Aust N Z J Psychiatry 51(6):595-603. https:// doi.org/10.1177/0004867416665483

26. Veale D, Eshkevari E, Kanakam N, Ellison N, Costa A, Werner T (2014) The appearance anxiety inventory: validation of a process measure in the treatment of body dysmorphic disorder. Behav Cogn Psychother 42(5):605-616. https://doi.org/10.1017/S1352 465813000556

27. Mastro S, Zimmer-Gembeck MJ, Webb HJ, Farrell L, Waters A (2016) Young adolescents' appearance anxiety and body dysmorphic symptoms: social problems, self-perceptions and comorbidities. J Obs Compuls Relat Disord 8:50-55. https://doi.org/10. 1016/j.jocrd.2015.12.001
28. Scahill L, Riddle MA, McSwiggin-Hardin M, Ort SI, King RA, Goodman WK et al (1997) Children's Yale-Brown Obsessive Compulsive scale: reliability and validity. J Am Acad Child Adolesc Psychiatry 36(6):844-852. https://doi.org/10.1097/00004 583-199706000-00023

29. Piacentini J, Jaffer M, Bergman RL, McCracken J, Keller M (2001) Measuring impairment in childhood OCD: psychometric properties of the COIS. American Academy of Child and Adolescent Psychiatry, Washington, p 146

30. Shaffer D, Gould MS, Brasie J, Ambrosini P, Fisher P, Bird H et al (1983) A Children's Global Assessment scale (CGAS). Arch Gen Psychiatry 40(11):1228-1231. https://doi.org/10.1001/archpsyc. 1983.01790100074010

31. Lundh A, Kowalski J, Sundberg CJ, Gumpert C, Landén M (2010) Children's Global Assessment scale (CGAS) in a naturalistic clinical setting: inter-rater reliability and comparison with expert ratings. Psychiatry Res 177(1-2):206-210. https://doi.org/10.1016/j. psychres.2010.02.006

32. Green B, Shirk S, Hanze D, Wanstrath J (1994) The Children's Global Assessment scale in clinical practice: an empirical evaluation. J Am Acad Child Adolesc Psychiatry 33(8):1158-1164. https://doi.org/10.1097/00004583-199410000-00011

33. Foa EB, Coles M, Huppert JD, Pasupuleti RV, Franklin ME, March J (2010) Development and validation of a child version of the obsessive compulsive inventory. Behav Ther 41(1):121-132. https://doi.org/10.1016/j.beth.2009.02.001

34. Nunnally JC, Bernstein IH (1994) Psychometric theory, 3rd edn. McGraw-Hill Professional, New York

35. Pinto A, Van Noppen B, Calvocoressi L (2013) Development and preliminary psychometric evaluation of a self-rated version of the family accommodation scale for obsessive-compulsive disorder. J Obs Compuls Relat Disord 2(4):457-465. https://doi.org/10. 1016/j.jocrd.2012.06.001

36. March JS (2012) Multidimensional anxiety scale for children, 2nd edn. Multi-Health Systems Inc., North Tonawanda

37. Fraccaro RL, Stelnicki AM, Nordstokke DW (2015) Test review: multidimensional anxiety scale for children by J. S. March. Can J Sch Psychol 30(1):70-77. https://doi.org/10.1177/0829573514 542924

38. Kovacs M (1992) Children's depression inventory 2. Multi-Health Systems Inc., North Tonawanda

39. Bae Y (2012) Test review: children's depression inventory 2 (CDI 2). J Psychoeduc Assess 30(3):304-308. https://doi.org/10.1177/ 0734282911426407

40. Achenbach TM, Rescoria LA (2001) Manual for the ASEBA school-age forms \& profiles. University of Vermont, Burlington

41. Nakamura BJ, Ebesutani C, Bernstein A, Chorpita BF (2009) A psychometric analysis of the child behavior checklist DSM-oriented scales. J Psychopathol Behav Assess 31:178-189. https:// doi.org/10.1007/s10862-008-9119-8

42. Garnefski N, Kraaij V, Spinhoven P (2001) Cognitive emotion regulation questionnaire. Leiden University, Leiden

43. Garnefski N, Kraaij V (2005) Child version of the cognitive emotion regulation questionnaire. Leiden University, Leiden

44. Garnefski N, Rieffe C, Jellesma F, Terwogt MM, Kraaij V (2007) Cognitive emotion regulation strategies and emotional problems in 9-11-year-old children: the development of an instrument. Eur Child Adolesc Psychiatry. https://doi.org/10.1007/ s00787-006-0562-3

45. Garnefski N, Kraaij V (2007) The cognitive emotion regulation questionnaire. Eur J Psychol Assess 23(3):141-149. https://doi. org/10.1027/1015-5759.23.3.141

46. Gullone E, Taffe J (2012) The emotion regulation questionnaire for children and adolescents (ERQ-CA): a psychometric 
evaluation. Psychol Assess 24(2):409-417. https://doi.org/10. 1037/a0025777

47. Farrell LJ, Waters AM, Tiralongo E, Mathieu S, McKenzie M, Garbaharran V et al (2021) Efficacy of d-cycloserine augmented intensive cognitive-behavioural therapy for paediatric obsessivecompulsive disorder: a randomised clinical trial. Manuscript submitted for publication

48. Schober P, Boer C, Schwarte LA (2018) Correlation coefficients: appropriate use and interpretation. Anesth Analg 126(5):17631768. https://doi.org/10.1213/ane.0000000000002864

49. Bishara AJ, Hittner JB (2012) Testing the significance of a correlation with nonnormal data: comparison of Pearson, Spearman, transformation, and resampling approaches. Psychol Methods 17(3):399-417. https://doi.org/10.1037/a0028087

50. Pek J, Wong O, Wong ACM (2018) How to address non-normality: a taxonomy of approaches, reviewed, and illustrated. Front Psychol. https://doi.org/10.3389/fpsyg.2018.02104

51. Jaccard J, Guilamo-Ramos V (2002) Analysis of variance frameworks in clinical child and adolescent psychology: Issues and recommendations. J Clin Child Adolesc Psychol 31(1):130-146. https://doi.org/10.1207/s15374424jccp3101_15

52. Storch EA, Lewin AB, De Nadai AS, Murphy TK (2010) Defining treatment response and remission in obsessive-compulsive disorder: a signal detection analysis of the Children's Yale-Brown Obsessive Compulsive scale. J Am Acad Child Adolesc Psychiatry 49(7):708-717. https://doi.org/10.1016/j.jaac.2010.04.005

53. Enders CK (2010) Applied missing data analysis. Guilford Press, New York

54. Sullivan GM, Feinn R (2012) Using effect size-or why the P value is not enough. J Grad Med Educ 4(3):279-282. https://doi. org/10.4300/jgme-d-12-00156.1

55. Hicks BM, Blonigen DM, Kramer MD, Krueger RF, Patrick CJ, Iacono WG et al (2007) Gender differences and developmental change in externalizing disorders from late adolescence to early adulthood: a longitudinal twin study. J Abnorm Psychol 116(3):433-447. https://doi.org/10.1037/0021-843x.116.3.433

56. Taylor S (2011) Early versus late onset obsessive-compulsive disorder: evidence for distinct subtypes. Clin Psychol Rev 31(7):1083-1100. https://doi.org/10.1016/j.cpr.2011.06.007

57. Walitza S, Van Ameringen M, Geller D (2020) Early detection and intervention for obsessive-compulsive disorder in childhood and adolescence. Lancet Child Adolesc Health 4(2):99-101. https:// doi.org/10.1016/S2352-4642(19)30376-1

58. Phillips KA (2015) Body dysmorphic disorder: clinical aspects and relationship to obsessive-compulsive disorder. Focus 13(2):162-174. https://doi.org/10.1176/appi.focus.130205

59. Kenward MG, Molenberghs G (2009) Last observation carried forward: a crystal ball? J Biopharm Stat 19(5):872-888. https:// doi.org/10.1080/10543400903105406

60. Crerand CE, Menard W, Phillips KA (2010) Surgical and minimally invasive cosmetic procedures among persons with body dysmorphic disorder. Ann Plast Surg 65(1):11-16. https://doi.org/ 10.1097/sap.0b013e3181bba08f

61. Kelly MM, Phillips KA (2012) Phenomenology and epidemiology of body dysmorphic disorder. In: Steketee G (ed) The Oxford handbook of obsessive compulsive and spectrum disorders. Oxford University Press, Oxford, pp 48-69

Publisher's Note Springer Nature remains neutral with regard to jurisdictional claims in published maps and institutional affiliations. 